\title{
Prevalence and Related Factors of Vitamin D Deficiency in Critically III Patients
}

\author{
Hyun Jung Kim, M.D. ${ }^{{ }^{*}}$, Min Su Sohn, M.D. ${ }^{2^{*}}$, and Eun Young Choi, M.D., Ph.D. ${ }^{3}$ \\ ${ }^{1}$ Division of Pulmonary and Critical Care Medicine, Department of Internal Medicine, Kyungpook National University Hospital, Kyungpook National University School of Medicine, \\ Daegu; ' 2 Division of Pulmonary and Critical Care Medicine, Department of Internal Medicine, Keimyung University Dongsan Medical Center, Daegu; ${ }^{3}$ Division of Pulmonary and Critical \\ Care Medicine, Department of Internal Medicine, Yeungnam University Hospital, Regional Respiratory Center, Yeungnam University College of Medicine, Daegu, Korea
}

Background: To identify the prevalence and related factors for vitamin D deficiency in the patients who admitted to the medical intensive care unit (ICU) of a Korean tertiary care hospital.

Methods: We retrospectively analyzed the data from ICU patients requiring mechanical ventilation (MV) for a period of $>48 \mathrm{~h}$ to identify the prevalence and associated factors for vitamin D deficiency. Vitamin D deficiency was defined as serum 25-hydroxyvitamin D $[25(\mathrm{OH}) \mathrm{D}]$ level $<20 \mathrm{ng} / \mathrm{mL}$.

Results: Among 570 patients admitted to the ICU, 221 were enrolled in the study, 194 in the vitamin D deficient group and 27 in the non-deficient group. Prevalence of vitamin D deficiency in critically ill patients was $87.8 \%$. The patient age was lower in the vitamin $D$ deficient group compared with the non-deficient group (64.4 \pm 15.4 vs. $71.0 \pm 9.6$ years, $p=0.049)$. A higher acute physiology and chronic health evaluation II (APACHE II) score (odds ratio [OR] 1.23, 95\% confidence interval [CI] 1.10-1.37) and chronic illness (OR $3.12,95 \% \mathrm{Cl} 1.08-9.01)$ were associated with vitamin D deficiency after adjusting for age and body mass index. Clinical outcomes of duration of MV, ICU stay, and 28- and 90-day mortality rates were not significantly different between the vitamin D deficient and nondeficient groups.

Conclusions: Vitamin D deficiency was common in critically ill patients, particularly among younger patients. Higher APACHE II score and chronic illness were associated with vitamin D deficiency.

Key Words: 25-hydroxyvitamin D; calcitriol; critical care; intensive care units; vitamin D deficiency.

Vitamin D deficiency is common in critically ill patients and associated with a variety of poor clinical outcomes, including increased in-hospital mortality, prolonged intensive care unit (ICU) stay, blood stream infection, and prolonged use of mechanical ventilation (MV).[1-6] Among critically ill patients requiring MV support, reducing the durations of both MV and ICU stays is important for improving clinical outcome. Understanding the prevalence and predisposing

Received on April 5, 2016 Revised on July 18, 2016

Accepted on October 12, 2016

Correspondence to: Eun Young Choi, Division of Pulmonology and Critical Care Medicine, Department of Internal Medicine, Yeungnam University Hospital, Regional Respiratory Center, Yeungnam University College of Medicine, 170 Hyeonchung-ro, Namgu, Daegu 42415, Korea

Tel: +82-53-620-3828, Fax: +82-53-654-8386

E-mail: letact@daum.net

*These authors contributed equally to this paper.

*No potential conflict of interest relevant to this article was reported. factors related to vitamin D deficiency is therefore important for improving outcomes in critically ill patients.

Vitamin D affects a wide range of biological processes, including cell proliferation and differentiation, regulation of inflammation, immunomodulation, muscle strength, in addition to bone formation and electrolyte homeostasis.[7] Clinical outcomes associated with vitamin D deficiency include resistance to infection, cardiovascular disease, 
and insulin resistance.[8-11] However, despite these wide-ranging pleiotropic effects, there is no common definition for adequate serum concentration of vitamin $\mathrm{D}$, measured as 25-hydroxyvitamin D [25(OH)D].[12] Historically, vitamin $\mathrm{D}$ deficiency has been defined as 25(OH)D level $<20 \mathrm{ng} / \mathrm{mL}(50 \mathrm{nmol} / \mathrm{L})$, with vitamin D insufficiency classified as $21-29 \mathrm{ng} / \mathrm{mL}(52.5-72.5 \mathrm{nmol} /$ L) $25(\mathrm{OH}) \mathrm{D}$ according to the Institute of Medicine.[13] Because vitamin D is synthesized in response to ultraviolet light, sun exposure remains important for maintaining a healthy level of vitamin D. In recent years, sun exposure has declined because people are spending more time indoors, a phenomenon particularly common in younger individuals. $[14,15]$ Since very few foods naturally contain vitamin $\mathrm{D}$, natural sunlight remains the major source of vitamin D for most individuals.[7] Accordingly, the prevalence of vitamin D deficiency remains strongly associated with factors affecting ultraviolet light intensity, including geographic location, skin tone, and time of year.[16,17]

The Korean climate is characterized by four distinct seasons, with the majority of the population residing in cities and spending much of their time indoors. As these factors are likely to affect serum vitamin D level, we performed a retrospective study evaluating the prevalence and related factors of vitamin D deficiency in the patients who admitted to Korean tertiary care hospital.

\section{Materials and Methods}

\section{1) Patients and study design}

This retrospective observational study reviewed the medical records of critically ill patients who were admitted to the ICU between January 2012 and October 2014. Patients were included if they met the following criteria: 18 years of age or older, serum vitamin D level measured at ICU admission; and required MV for $>48 \mathrm{~h}$. Vitamin D deficiency was defined as serum 25(OH)D level $<20$ $\mathrm{ng} / \mathrm{mL}(50 \mathrm{nmol} / \mathrm{L})$. $[7,13]$ We classified patients into either a vitamin $\mathrm{D}$ deficient or non-deficient group. To evaluate the related factors of vitamin D deficiency, we compared the clinical characteristics of the two groups. We analyzed clinical outcomes between the vitamin D deficient group and non-deficient group to evaluate the effect of vitamin D deficiency in critically ill patients.

Data were gathered from medical records using a structured form. Patient data included baseline demographic characteristics, body mass index (BMI), comorbidities, Acute Physiology and Chronic Health Evaluation II (APACHE II) score, and clinical laboratory data. Clinical outcomes included duration of MV, length of ICU stay and hospitalization, and 28- and 90-day mortality rates. The ICU is operated by a team of day-time ICU staff, along with day- and night-time duty residents.

\section{2) Measurement of serum vitamin $D$ concentration}

Blood samples were obtained within $24 \mathrm{~h}$ of ICU admission. Serum circulating 25(OH)D level was measured using a chemiluminescent immunoassay at the Green Cross Laboratory (Daegu, Korea).

\section{3) Statistical analysis}

Descriptive statistics included frequencies and percentages for categorical variables and means and standard deviations for continuous variables. Continuous variables were analyzed using a $t$-test or Mann-Whitney $U$ test as appropriate; categorical variables were analyzed using a $\chi^{2}$ or Fisher's exact test. Multivariable logistic regression models were fitted to identify associated factors of vitamin D deficiency. The odds ratios (ORs) for vitamin D deficiency were estimated after adjusting for potential confounders. Data were analyzed using SPSS 17.0 for Windows (SPSS Inc., Chicago, IL, USA). All tests were two-tailed, and a pvalue $<0.05$ was considered statistically significant. Data were presented as mean \pm standard deviation.

\section{4) Ethics statement}

This study was approved by the Yeungnam University Hospital Institutional Review Board. All patient data and information were confidential. 


\section{Results}

\section{1) Baseline characteristics}

A total of 570 patients were admitted to the medical ICU for the period of the investigation, of whom 227 had serum vitamin D level results. Six patients were excluded due to use of MV for $<48 \mathrm{~h}$, resulting in a final study cohort of 221 patients (Fig. 1).

The baseline characteristics of the enrolled patients are shown in Table 1. The age of the enrolled patients was $65.2 \pm 14.9$ years, and $67.4 \%(149 / 221)$ were male. The serum vitamin D concentration was $11.8 \pm 7.9 \mathrm{ng} / \mathrm{mL}$,

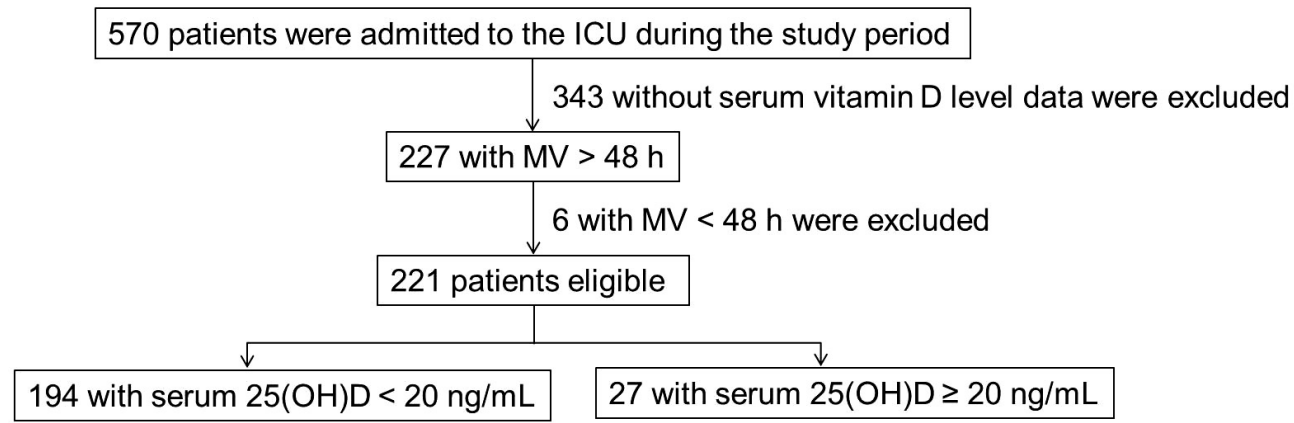

Fig. 1. Flow chart of enrolled patients in this study. ICU: intensive care unit; MV: mechanical ventilator; 25(OH)D: 25-hydroxyvita$\min \mathrm{D}$.

Table 1. Baseline Characteristics

\begin{tabular}{|c|c|c|c|}
\hline \multirow[b]{2}{*}{ Characteristic } & \multicolumn{2}{|c|}{ Serum 25(OH)D level } & \multirow[b]{2}{*}{$p$-value } \\
\hline & $\begin{array}{c}<20 \mathrm{ng} / \mathrm{mL} \\
\mathrm{n}=194\end{array}$ & $\begin{array}{c}\geq 20 \mathrm{ng} / \mathrm{mL} \\
n=27\end{array}$ & \\
\hline Sex (male) & $132(68.0)$ & $17(63.0)$ & 0.598 \\
\hline Age (years) & $64.4 \pm 15.35$ & $71.0 \pm 9.60$ & 0.049 \\
\hline BMl $\left(\mathrm{kg} / \mathrm{m}^{2}\right)$ & $22.5 \pm 4.84$ & $20.5 \pm 4.01$ & 0.033 \\
\hline Ever-smokers & $56(28.9)$ & $3(11.1)$ & 0.051 \\
\hline APACHE $\|$ & $21 \pm 6$ & $16 \pm 4$ & $<0.001$ \\
\hline Comorbidities & $150(89.3)$ & $18(66.7)$ & 0.224 \\
\hline Cardiovascular disease & $26(13.4)$ & $2(7.4)$ & \\
\hline Chronic pulmonary disease & $57(29.4)$ & $7(25.9)$ & \\
\hline Cerebrovascular disease & $26(13.4)$ & $9(33.3)$ & \\
\hline Diabetes mellitus & $72(37.1)$ & $5(18.5)$ & \\
\hline Liver disease & $18(9.3)$ & $1(3.7)$ & \\
\hline Renal disease & $23(11.9)$ & $1(3.7)$ & \\
\hline Malignancy & $16(8.2)$ & $1(3.7)$ & \\
\hline Gastric ulcer & $7(3.6)$ & $0(0)$ & \\
\hline Connective tissue disease & $8(4.1)$ & $3(11.1)$ & \\
\hline Season of ICU admission & & & 0.360 \\
\hline Spring & $68(35.1)$ & $5(18.5)$ & \\
\hline Summer & $56(28.9)$ & $11(40.7)$ & \\
\hline Fall & $31(16.0)$ & $5(18.5)$ & \\
\hline Winter & $39(20.1)$ & $6(22.2)$ & \\
\hline Serum 25(OH)D (ng/mL) & $9.6 \pm 4.9$ & $27.7 \pm 7.3$ & $<0.001$ \\
\hline
\end{tabular}

Values are presented as mean \pm standard deviation or number (\%).

25(OH)D: 25-hydroxyvitamin D; BMl: body mass index; APACHE II: acute physiology and chronic health evaluation II; ICU: intensive care unit. 
Table 2. Proportions of comorbidity and vitamin D deficiency and mean serum vitamin D level according to age

\begin{tabular}{|c|c|c|c|c|}
\hline \multirow{2}{*}{ Age } & \multirow{2}{*}{ Comorbidity } & \multicolumn{2}{|c|}{ Serum 25(OH)D level } & \multirow{2}{*}{$\begin{array}{l}\text { Mean serum } 25(\mathrm{OH}) \mathrm{D} \text { level } \\
(\mathrm{ng} / \mathrm{mL})\end{array}$} \\
\hline & & $<20 \mathrm{ng} / \mathrm{mL}$ & $\geq 20 \mathrm{ng} / \mathrm{mL}$ & \\
\hline $20-29$ & $1(14.3)$ & $7(100)$ & $0(0)$ & $11.0 \pm 7.1$ \\
\hline $30-39$ & $5(41.7)$ & $12(100)$ & $0(0)$ & $7.0 \pm 3.5$ \\
\hline $40-49$ & $12(75.0)$ & $14(87.5)$ & $2(12.5)$ & $9.4 \pm 8.4$ \\
\hline $50-59$ & $17(68.0)$ & $25(100)$ & $0(0)$ & $8.7 \pm 4.2$ \\
\hline $60-69$ & $45(81.8)$ & 49 (89.1) & $6(10.9)$ & $12.4 \pm 7.5$ \\
\hline $70-79$ & 61 (79.2) & $63(81.8)$ & 14 (18.2) & $13.3 \pm 7.4$ \\
\hline $80-89$ & $26(92.9)$ & $23(82.1)$ & 5 (17.9) & $13.6 \pm 11.7$ \\
\hline 90- & $1(100.0)$ & $1(100)$ & $0(0)$ & \\
\hline Total & $168(76.0)$ & $194(87.8)$ & $27(12.2)$ & \\
\hline
\end{tabular}

Values are presented as mean \pm standard deviation or number (\%).

25(OH)D: 25-hydroxyvitamin D.

Table 3. Associated factors of vitamin D deficiency

\begin{tabular}{lcccccc}
\hline \multirow{2}{*}{ Factors } & \multicolumn{2}{c}{ Univariable analysis } & & & \multicolumn{2}{c}{ Multivariable analysis } \\
\cline { 2 - 3 } Age & OR of vitamin D deficiency & & p-value & & OR of vitamin D deficiency & p-value \\
BMI & $0.96(0.93-1.00)$ & 0.034 & & $0.95(0.91-0.96)$ & 0.007 \\
Comorbidity & $1.13(1.01-1.26)$ & 0.035 & & $1.12(0.99-1.28)$ & 0.078 \\
APACHE II & $1.71(0.72-4.06)$ & 0.228 & & $3.12(1.08-9.01)$ & 0.036 \\
\hline
\end{tabular}

Values are presented as OR (95\% confidence interval).

OR: odds ratio; BMI: body mass index; APACHE II: acute physiology and chronic health evaluation II.

and $194(87.8 \%)$ patients were classified as vitamin D deficient. Mean serum vitamin D level was $10.9 \pm 7.9$, $12.9 \pm 8.5,12.8 \pm 8.1$, and $11.0 \pm 6.6 \mathrm{ng} / \mathrm{mL}$ in spring, summer, autumn, and winter, respectively. Vitamin D levels did not differ between males and females $(11.7 \pm$ 7.0 vs. $12.2 \pm 9.6 \mathrm{ng} / \mathrm{mL}, \mathrm{p}=0.661)$.

The serum vitamin $\mathrm{D}$ level in the deficient group was $9.6 \pm 4.9 \mathrm{ng} / \mathrm{mL}$, while that in the non-deficient group was $27.7 \pm 7.3 \mathrm{ng} / \mathrm{mL}$. The age of the vitamin D deficient group was lower than that of the non-deficient group (64.4 \pm 15.4 vs. $71.0 \pm 9.6$ years, $\mathrm{p}=0.049)$. BMI $(22.5 \pm 4.8$ vs. $20.5 \pm 4.0, \mathrm{p}=0.033)$ and APACHE II score $(21 \pm 6$ vs. $16 \pm 4, p<0.001)$ were significantly higher in the vitamin D deficient group than in the non-deficient group. The vitamin D deficient group also had more comorbid conditions such as diabetes and renal disease compared with the non-deficient group, although these differences did not reach statistical significance (Table 1).
Average serum vitamin D level was the lowest among patients in their $30 \mathrm{~s}(7.0 \pm 3.5 \mathrm{ng} / \mathrm{mL}$; Table 2). Mean serum vitamin $\mathrm{D}$ level was higher in patients $>50$ years of age than in those $<50$ years of age $(12.4 \pm 8.0$ vs. $8.9 \pm 6.8$ $\mathrm{ng} / \mathrm{mL}, \mathrm{p}=0.016$ ).

\section{2) Associated factors of vitamin D deficiency}

A weak correlation was observed between serum vitamin D level and APACHE II score $\left(\mathrm{r}^{2}=0.18, \mathrm{p}<0.001\right)$. Younger age, higher BMI, and APACHE II score were significantly associated with vitamin D deficiency based on simple logistic regression analysis. On multivariable analysis using the logistic regression method, a high APACHE II score (OR 1.23, 95\% confidence interval [CI] 1.10-1.37, $\mathrm{p}<0.001)$ and underlying comorbidity (OR 3.12, 95\% CI 1.08-9.01, $\mathrm{p}=0.036$ ) were identified as independent predictors of vitamin D deficiency at ICU admission (Table 3). 
Table 4. Clinical outcomes according to vitamin D deficiency

\begin{tabular}{|c|c|c|c|}
\hline \multirow{2}{*}{ Clinical outcome } & \multicolumn{2}{|c|}{ Serum 25(OH)D level } & \multirow{2}{*}{ p-value } \\
\hline & $<20 \mathrm{ng} / \mathrm{mL}$ & $\geq 20 \mathrm{ng} / \mathrm{mL}$ & \\
\hline 28-day mortality & $37(19.1)$ & $7(25.9)$ & 0.403 \\
\hline 90-day mortality & $49(25.3)$ & $9(33.3)$ & 0.372 \\
\hline Duration of MV (days) & $14.9 \pm 34.0$ & $10.6 \pm 9.6$ & 0.519 \\
\hline Duration of ICU admission (days) & $17.9 \pm 34.4$ & $16.0 \pm 13.1$ & 0.778 \\
\hline Duration of hospitalization (days) & $35.0 \pm 59.8$ & $31.3 \pm 27.4$ & 0.748 \\
\hline
\end{tabular}

Values are presented as mean \pm standard deviation or number (\%).

25(OH)D: 25-hydroxyvitamin D; MV: mechanical ventilation; ICU: intensive care unit.

\section{3) Relationship between vitamin D deficiency and clini- cal outcomes}

Neither 28- nor 90-day mortality rate was associated with vitamin D deficiency (deficient vs. non-deficient; $19.1 \%$ vs. $25.9 \%, \mathrm{p}=0.403$ for 28 -day mortality; $25.3 \%$ vs. $33.3 \%, p=0.372$ for 90 -day mortality). Length of MV care, duration of ICU stay, and hospitalization were not significantly different between vitamin $\mathrm{D}$ deficient and non-deficient groups (Table 4).

\section{Discussion}

Vitamin D deficiency was very common $(87.8 \%)$ in critically ill patients, particularly those younger than 50 years. Among the variables tested, high APACHE II score and presence of comorbidities were associated with vitamin D deficiency in critically ill patients.

Low levels of serum vitamin D were observed not only among the older patients with chronic diseases, but also among younger patients with no comorbidities. These observations are broadly consistent with a previous large survey of the Korean population,[14] showing vitamin $\mathrm{D}$ insufficiency to be a significant problem, particularly among younger residents. Elderly residents are also at an increased risk of vitamin D insufficiency, as the cutaneous synthesis of vitamin D declines with age.[18] These deficiencies become even more pronounced in critically ill patients, who often have lower serum 25(OH)D levels $(11.8 \pm 7.9$ vs. $15.2 \pm 7.3 \mathrm{ng} / \mathrm{mL}, \mathrm{p}<0.001)$ and a higher prevalence of vitamin D insufficiency ( $87.8 \%$ vs. $56.9 \%)$ compared with the general population.[14] Furthermore, another study showed that $80 \%$ of second-decade military personnel with pneumonia had vitamin D insufficiency $(10 \mathrm{ng} / \mathrm{mL} \leq 25(\mathrm{OH}) \mathrm{D}<30 \mathrm{ng} / \mathrm{mL})$, highlighting the strong relationship between vitamin D deficiency and susceptibility to disease.[19] The phenomenon of vitamin D deficiency in Korean youth appears to be directly related to industrialization. In Korea, young adults tend to gravitate toward urban areas and work primarily indoors, while elderly residents are more likely to live in rural areas and have outdoor jobs. This environmental difference may partially explain the phenomenon of greater vitamin D deficiency in the younger generation. Among our study population, vitamin D deficiency was more common in patients $<50$ years of age compared with those $>50$ years of age. One possible explanation for this observation is the study design, because patient inclusion was limited to those requiring MV for $>48 \mathrm{~h}$. Many elderly patients with chronic disease often choose not to seek intensive care, which may also require MV, thus potentially affecting our results.

An inverse association between serum 25(OH)D level and BMI $>30 \mathrm{~kg} / \mathrm{m}^{2}$ was observed, suggesting that obesity is associated with vitamin D deficiency.[17,20] This study showed that BMI in the vitamin D deficient group was significantly higher than non-deficient group; however, BMI was not identified as an independently predictable factor of vitamin D deficiency based on multivariable logistic regression. Although mean BMI was greater in the vitamin D deficiency group, the mean BMIs in 
both the deficient and non-deficient groups fell within the normal range according to World Health Organization obesity guidelines.

Previous researches have suggested that serum vitamin D level is in inverse proportion to serum calcium and albumin level. However, no such association was observed in the present study.[21] Although the comorbidities examined did not correlate with vitamin D deficiency, patients with at least one underlying disease of any kind were at a greater risk of vitamin D deficiency. Among individual comorbidities, cerebrovascular disease was more prevalent in the vitamin D non-deficient group than in the vitamin D deficient group (13.4\% vs. $33.3 \%$ ), contrary to the general assumption that patients with cerebrovascular disease are less likely to have sufficient sun exposure. This apparent discrepancy highlights the myriad of factors contributing to vitamin D deficiency, suggesting that a performance-based outcome or severity of neurological sequelae may be a more informative outcome in this population. Considering the diverse roles of vitamin D, it may be useful to screen patients with existing comorbidities to assess serum vitamin D levels. A large-scale, randomized control trial examining the use of vitamin D supplementation in patients with chronic disease may also be warranted.

In contrast to previous reports on the relationship between clinical outcomes and vitamin D deficiency, our study did not demonstrate vitamin D deficiency to be associated with poor clinical outcomes.[1-4] A possible reason for this result is that the small number of subjects $(n=27)$ in the vitamin $D$ non-deficient groups was insufficient to show a meaningful difference in clinical outcomes. Additionally, the present study included all patients who were admitted to the medical ICU rather than those with a specific disease category; thus, the determinants of prognosis might be multifactorial.

The most significant limitation of this study was the small, single-center, retrospective design without sequential vitamin D blood sampling. While limited exposure to sunlight due to comorbidities and malnutrition are important causes of vitamin D deficiency, altered metabolism of vitamin $\mathrm{D}$ and parathyroid hormone during critical illness cannot be ruled out.[22,23] Assessment of serum parathyroid hormone and other metabolites related to vitamin D metabolism, along with follow-up assessment of serum vitamin D level, could have provided important insights.

Despite its wide-ranging role in human health, vitamin D replacement is seldom considered for critically ill patients. Previous studies have shown that both of enteral and parental nutritions supplied to critically ill patients. Previous studies have shown that both of enteral and parental nutritions supplied to critically ill patients were grossly inadequate for treating the vitamin D deficiency.[24] Furthermore, numerous studies have shown biological effect of vitamin $\mathrm{D}$, whereas few studies support the hypothesis that vitamin D therapy can improve outcomes,[25-28] with only short-term effects evaluated in adult ICU patients.[29] This lack of data regarding the usefulness of vitamin D therapy is further complicated by an absence of definitive protocols for vitamin D supplementation.[30] It is necessary to perform well-designed clinical trial regarding best methods for vitamin $\mathrm{D}$ replacement and association of clinical outcome with vitamin D replacement.

Collectively, vitamin D deficiency is common in critically ill patients, even among younger patients. Patients presenting with one or more comorbidity or a high APACHE II score are at an increased risk of vitamin D deficiency and should be monitored accordingly.

\section{ORCID}

Hyun Jung Kim ～http://orcid.org/0000-0002-1878-1111

Min Su Sohn http://orcid.org/0000-0001-9250-9696

Eun Young Choi http://orcid.org/0000-0003-2974-5447

\section{References}

1) Higgins DM, Wischmeyer PE, Queensland KM, Sillau SH, Sufit AJ, Heyland DK: Relationship of vi- 
tamin D deficiency to clinical outcomes in critically ill patients. JPEN J Parenter Enteral Nutr 2012; 36: 713-20.

2) Arnson Y, Gringauz I, Itzhaky D, Amital H: Vitamin $\mathrm{D}$ deficiency is associated with poor outcomes and increased mortality in severely ill patients. QJM 2012; 105: 633-9.

3) Rech MA, Hunsaker T, Rodriguez J: Deficiency in 25-hydroxyvitamin D and 30-day mortality in patients with severe sepsis and septic shock. Am J Crit Care 2014; 23: e72-9.

4) Matthews LR, Ahmed Y, Wilson KL, Griggs DD, Danner OK: Worsening severity of vitamin D deficiency is associated with increased length of stay, surgical intensive care unit cost, and mortality rate in surgical intensive care unit patients. Am J Surg 2012; 204: 37-43.

5) Quraishi SA, McCarthy C, Blum L, Cobb JP, Camargo CA Jr: Plasma 25-hydroxyvitamin D levels at initiation of care and duration of mechanical ventilation in critically ill surgical patients. JPEN J Parenter Enteral Nutr 2016; 40: 273-8.

6) Verceles AC, Weiler B, Koldobskiy D, Goldberg AP, Netzer G, Sorkin JD: Association between vitamin D status and weaning from prolonged mechanical ventilation in survivors of critical illness. Respir Care 2015; 60: 1033-9.

7) Holick MF: Vitamin D Deficiency. N Engl J Med 2007; 357: 266-81.

8) Mora JR, Iwata M, von Andrian UH: Vitamin effects on the immune system: vitamins A and D take centre stage. Nat Rev Immunol 2008; 8: 685-98.

9) Pilz S, März W, Wellnitz B, Seelhorst U, FahrleitnerPammer A, Dimai HP, et al: Association of vitamin $\mathrm{D}$ deficiency with heart failure and sudden cardiac death in a large cross-sectional study of patients referred for coronary angiography. J Clin Endocrinol Metab 2008; 93: 3927-35.

10) Chiu KC, Chu A, Go VL, Saad MF: Hypovitaminosis $\mathrm{D}$ is associated with insulin resistance and beta cell dysfunction. Am J Clin Nutr 2004; 79: 820-5.
11) Schöttker B, Haug U, Schomburg L, Köhrle J, Perna L, Müller H, et al: Strong associations of 25-hydroxyvitamin D concentrations with all-cause, cardiovascular, cancer, and respiratory disease mortality in a large cohort study. Am J Clin Nutr 2013; 97: 782-93.

12) Ross AC, Manson JE, Abrams SA, Aloia JF, Brannon PM, Clinton SK, et al: The 2011 report on dietary reference intakes for calcium and vitamin $\mathrm{D}$ from the Institute of Medicine: what clinicians need to know. J Clin Endocrinol Metab 2011; 96: 53-8.

13) Holick MF, Binkley NC, Bischoff-Ferrari HA, Gordon CM, Hanley DA, Heaney RP, et al: Evaluation, treatment, and prevention of vitamin D deficiency: an Endocrine Society clinical practice guideline. J Clin Endocrinol Metab 2011; 96: 1911-30.

14) Choi HS, Oh HJ, Choi H, Choi WH, Kim JG, Kim KM, et al: Vitamin D insufficiency in Korea-a greater threat to younger generation: the Korea National Health and Nutrition Examination Survey (KNHANES) 2008. J Clin Endocrinol Metab 2011; 96: 643-51.

15) Vieth R, Cole DE, Hawker GA, Trang HM, Rubin LA: Wintertime vitamin D insufficiency is common in young Canadian women, and their vitamin D intake does not prevent it. Eur J Clin Nutr 2001; 55: 1091-7.

16) Clemens TL, Adams JS, Henderson SL, Holick MF: Increased skin pigment reduces the capacity of skin to synthesise vitamin D3. Lancet 1982; 319: 74-6.

17) Greene-Finestone LS, Berger C, de, de Groh M, Hanley DA, Hidiroglou N, Sarafin K, et al: 25-Hydroxyvitamin D in Canadian adults: biological, environmental, and behavioral correlates. Osteoporos Int 2011; 22: 1389-99.

18) MacLaughlin J, Holick MF: Aging decreases the capacity of human skin to produce vitamin D3. J Clin Invest $1985 ; 76: 1536-8$.

19) Jhun BW, Kim SJ, Kim K, Lee JE, Hong DJ: Vitamin D status in South Korean military personnel with acute eosinophilic pneumonia: a pilot study. 
Tuberc Respir Dis (Seoul) 2015; 78: 232-8.

20) Wortsman J, Matsuoka LY, Chen TC, Lu Z, Holick MF: Decreased bioavailability of vitamin D in obesity. Am J Clin Nutr 2000; 72: 690-3.

21) Lucidarme O, Messai E, Mazzoni T, Arcade M, du Cheyron D: Incidence and risk factors of vitamin D deficiency in critically ill patients: results from a prospective observational study. Intensive Care Med 2010; 36: 1609-11.

22) Lee P, Eisman JA, Center JR: Vitamin D deficiency in critically ill patients. N Engl J Med 2009; 360: 1912-4.

23) Lee P: Vitamin D metabolism and deficiency in critical illness. Best Pract Res Clin Endocrinol Metab 2011; 25: 769-81.

24) Pittas AG, Laskowski U, Kos L, Saltzman E: Role of vitamin $\mathrm{D}$ in adults requiring nutrition support. JPEN J Parenter Enteral Nutr 2010; 34: 70-8.

25) Thadhani R, Appelbaum E, Pritchett Y, Chang Y, Wenger J, Tamez H, et al: Vitamin D therapy and cardiac structure and function in patients with chronic kidney disease: the PRIMO randomized controlled trial. JAMA 2012; 307: 674-84.

26) Nair P, Venkatesh B, Lee P, Kerr S, Hoechter DJ, Dimeski G, et al: A randomized study of a single dose of intramuscular cholecalciferol in critically ill adults. Crit Care Med 2015; 43: 2313-20.

27) Amrein K, Schnedl C, Holl A, Riedl R, Christopher $\mathrm{K}$, Pachler C, et al: Effect of high-dose vitamin $\mathrm{d} 3$ on hospital length of stay in critically ill patients with vitamin d deficiency: the VITdAL-ICU randomized clinical trial. JAMA 2014; 312: 1520-30.

28) Manaseki-Holland S, Maroof Z, Bruce J, Mughal MZ, Masher MI, Bhutta ZA, et al: Effect on the incidence of pneumonia of vitamin $\mathrm{D}$ supplementation by quarterly bolus dose to infants in Kabul: a randomised controlled superiority trial. Lancet 2012; 379: 1419-27.

29) Amrein K, Sourij H, Wagner G, Holl A, Pieber TR, Smolle KH, et al: Short-term effects of high-dose oral vitamin D3 in critically ill vitamin D deficient patients: a randomized, double-blind, placebo-controlled pilot study. Crit Care 2011; 15: R104.

30) Mata-Granados J, Vargas-Vasserot J, Ferreiro-Vera C, Luque de Castro ML, Pavón RG, Quesada Gómez JM: Evaluation of vitamin D endocrine system (VDES) status and response to treatment of patients in intensive care units (ICUs) using an on-line SPELC-MS/MS method. J Steroid Biochem Mol Biol 2010; 121: 452-5. 